This is an accepted manuscript published as

Cetera-Włodarczyk, A., et al (2019). National e-resources of Shakespeare translations in Europe: (Dis)assembling the black box. Cahiers

Élisabéthains: A Biannual Journal of English Renaissance Studies, 99(1), 89-101. https://doi.org/10.1177/0184767819835567

TITLE: $\quad$ National e-Resources of Shakespeare Translations in Europe:

(Dis)assembling the Black Box

AUTHORS: Anna Cetera-Wlodarczyk, University of Warsaw

Jesús Tronch, University of Valencia

Pavel Drábek, University of Hull

Boris Gaydin, Moscow University for the Humanities

Vladimir Makarov, St. Tikhon's Orthodox University in Moscow

Beatrice Montorfano, University of Pisa

Sara Soncini, University of Pisa

Nikolay Zakharov, Moscow University for the Humanities

ABSTRACT:

This paper discusses the construction, operation and scholarly usefulness of electronic resources of Shakespeare translations. In particular, it offers an overview of several existing European digital resources of Shakespeare translations by singling out trends, challenges, and new vistas of research; describing the content, editing policies and functionalities of selected European projects, already in operation or currently assembled; and discussing the aims and major difficulties faced by the researchers, the choice of navigation and search tools, the possibilities of integrating national repositories with other resources, and the relation of translation e-resources to adjacent disciplines, including corpus linguistics or stylometry.

\title{
KEYWORDS
}

electronic resources, Shakespeare, translation, Europe, editing 


\section{National e-Resources of Shakespeare Translations in Europe: (Dis)assembling the Black Box ${ }^{1}$}

'The documents we fashion in the present record the same burden of their own making as the documents we inherit from the past', warns Jerome McGann in his watchful analysis of the consequences of digital revolutions in humanities. ${ }^{2}$ Intuitively true, McGann's insight may appear irrelevant in the case of digitalising national resources of translations, Shakespeare or otherwise, which themselves document past literary engagements and cannot be altered without infringing copyright. And yet it is also literary translations which prove particularly sensitive to the passage of time, and can neither be properly assessed nor even understood without careful positioning against the cultural context of their age. Indeed, it is this context which rapidly complicates and diversifies when all translations, past and new, are made to cohabit in vast digital environments.

Spurred by the developments in Translation Studies in recent decades, Shakespeare translations have been subject to intense scrutiny, revealing the interpretative potential of the originals as well as the ideological and aesthetic preferences of the hosting culture. The reinvigorated interest has brought into light hundreds of Shakespeare (re)translations, adaptations, abridgements, imitations etc., extant in print and in manuscript, settled in national canons or stored in theatrical archives. Needless to say, pulling together national resources reveals a wealth of new material, elucidating the hitherto neglected histories of the native culture. Yet, apart from insights into the rewriting practices of previous ages, the e-resources bear witness to the internal dynamics of the corpora with distinctive patterns of influence, imitation and denial, well-exceeding the apparently monolingual or monocultural lines of inquiry. The choice of the eresources represented in this essay reflects the composition of the panel held at the 2017 ESRA conference in Gdańsk, and therefore features only these projects whose leaders answered to a call by the panel convener. However, we believe, the article covers an important gap because such international gathering of electronic resources of Shakespeare translations has not been carried out before. The resources developed because of the interest and enthusiasm of their respective teams and the public funding they received. Needless to say, sharing experiences may prompt or consolidate akin enterprises.

Living in the age of revolution is never easy. On the one hand, researchers are tempted to seize the opportunities offered by the new media. On the other hand, the pace of innovations outruns the rate of absorption of new solutions, and the laboriously assembled e-resources all but too often fall into the traps of incompatibility. Irrespective of tricky technology, the construction of national e-repositories faces the traditional challenges of archival research but it also prompts more unsettling questions about the foundation of knowledge which we obtain and proliferate. Large corpora of Shakespeare translations document the extraordinary mobility of the Bard and reveal the impact that these texts have on the evolution of native registers, stylistics and literary genre. Many tendencies appear concurrent or similar but national e-resources cannot be readily studied from outside, though, naturally, the vision of the multilingual Shakespeare translation e-library appears very tempting. Given our knowledge about eShakespeare, what kind of dreams can we dream in this respect? Shall we wait till national e-resources emerge and consolidate or, perhaps, sit and confer so that the future projects fit into the existing (and emergent) scholarly landscape?

\section{E-Resources of European Shakespeare in Translation: Aims, Histories, Afterlife}


Perhaps the earliest electronic resource that made information on Shakespeare translations available is Shakespeare in Europe, ${ }^{3}$ developed at Basel University, specifically its "translators" section, which lists translations into thirty-three European languages (with very few of them hyperlinked to an openaccess HTML or PDF file). The fact that translations are grouped by language and not country confers a certain transnational character on this project.

From a national perspective, one of the pioneering digital projects bridging Shakespeare Studies and Translation Studies was Kapradi - The Electronic Library of Czech Translations of Early English Drama which eventually offered nearly five hundred texts of Shakespeare translations. ${ }^{4}$ The project, launched at Masaryk University in Brno, was executed in the years 2002-2006 and managed by a modest group of 2-3 researchers at a time, supported by a group of students. Its funding relied on the hosting institution's budget and state-funded research activity (Czech Academy of Sciences Grant Agency), and was closely connected to teaching. The predominantly Shakespearean sources comprised printed translations and theatrical playscripts beginning from the late eighteenth century. Many playwrights' works were preserved in manuscript and typewriter scripts (and therefore required keyboarding). The search for extant translations revealed many hitherto neglected texts of which some one hundred and fifty were entirely unknown, whereas about two hundred were held in hardly accessible private collections or stored in theatre archives. These texts were digitised and about half of them (due to limited funds) were made available in an online search tool that allowed comparing parallel passages.

It seems that Kapradi was not a digital project in its own right but rather an inspiring by-product of a wide-ranging investigation into the history of Shakespeare in Czech translation. The fact that the resulting knowledge was eventually processed into a book and an anthology seems to confirm such an approach. ${ }^{5}$ Consequently, the project showcases the transition from the traditional media of disseminating research results in humanities (i.e. monographs and anthologies) to the digital philosophy which aims to ensure a continuous access to some highly organised resources or datasets. Additionally, it illustrates the problem with the sustainability of electronic collections which - without extra efforts often vanish from the net when the project comes to its end or researchers relocate to other institutions.

The Italian project Shakespeare sulle scene italiane (Shakespeare on the Italian Stage) is part of a wider framework called Dislocazioni Transnazionali - Transnational Dislocations, set up by the University of Pisa in 2015. ${ }^{6}$ The mother project has a loose and heterogeneous structure, with three Shakespeare-related components developed with various scholarly and pedagogical objectives in mind. ${ }^{7}$ The database Shakespeare sulle scene italiane evidences predominantly the theatrical history of Shakespeare in Italy. Two researches work on the elaboration of this database and further additions hang strongly on the prolongation of funding. Equipped with an Italian-language interface only, the database offers a great variety of information on the productions (including information on the choice of translation $)^{8}$ but it is not meant to provide texts of the translations.

The project seems to be an example of the site constructed with multiple objectives in mind, and with the hope of gradually developing collections and functionalities. It offers information but does not warrant completeness and relies predominantly on importing information derived from the pre-existent printed sources of documentary nature (catalogues, almanacs, etc.) into a digitised environment. And yet it offers an interesting insight into the dynamics of theatrical reception, allowing an exploration of the interdependencies of translation, temporal context and directorial preferences.

The state-funded project Shakespeare in Spain within the Framework of His European Reception at the Universidad de Murcia appears to represent a radically different philosophy. ${ }^{9}$ Its team of scholars searches for new materials related to the reception of Shakespeare in Spain, collects and updates the existing resources, and publishes its findings and studies both in print and online. The project's website (on a server hosted and maintained by the university) offers open access to two databases and an online library. The databases are on performances and on publication information of translations and adaptations into Spanish from 1772 to 2005. The e-library holds five contents created 
by Spanish authors: a bibliography of criticism 1764 and 2000, biographies of Shakespeare, pieces of criticism, adaptations, and translations (including the sonnets) from the nineteenth and early twentieth centuries. Except for the first Shakespeare translation into Spanish (Fernández de Moratín's 1798 Hamlet), hyperlinked to a modernised edition at the Biblioteca Virtual Miguel de Cervantes, ${ }^{10}$ all the translations are made available through PDFs from scanned documents. The current forty-five titles by fifteen different translators constitute the most comprehensive e-repository of Shakespeare translations into Spanish.

Based at the Universitat de València (Spain) are two open-access projects that include Shakespeare translations, although their scope is rather transnational. The Early Modern European Theatre project (EMOTHE) brings together selected plays from Italian, French, Spanish, English, and Portuguese drama of the sixteenth and seventeenth centuries, and selected translations and adaptations into these languages; it publishes reliable editions in an open-access policy, in single-text and paralleltext visualizations with original and translation(s); ${ }^{11}$ and gathers in a database not only texts but also information about the plays. The texts are encoded in Extensible Markup Language (XML) following the widely-used guidelines of the Text Encoding Initiative (TEI). ${ }^{12}$ For Shakespeare, EMOTHE reencodes texts from the Internet Shakespeare Editions and the Folger Digital Texts; and resorts to a single translator, François-Victor Hugo, for the French translations but to diverse translators for the other languages. As a state-funded project (involving twenty scholars in various degrees of commitment), EMOTHE continues the work of the ARTELOPE research group directed by Joan Oleza, initiated in 2000. ${ }^{13}$ Since 2016, The HIERONIMO Project (a digital environment for the research, edition and translation of early modern English drama $)^{14}$ has contributed to EMOTHE with multilingual editions of thirteen English plays: Timon of Athens is the only Shakespeare play as of May 2018, and nine Spanish translations and one Italian had not been published before. EMOTHE currently offers thirteen plays by Shakespeare and does not aspire to publish his complete dramatic canon.

The immense Russian resources have been assembled into several Shakespeare-related digital repositories, most of them ensuring access to some well-organised collections mapped in Cyrillic script. The first Russian repository of Shakespeare resources - Russkii Shekspir ${ }^{15}$ - was set up in 2007 and soon combined with Mir Shekspira - 'The World of Shakespeare: An Electronic Encyclopaedia' (2008). ${ }^{16}$ The sites have been developed and maintained thanks to the collaborative effort of about twenty academics, translators and theatre practitioners. Currently, the repository offers complete texts of selected Russian Shakespeare translations (in HTML and PDF format) which have fallen into the public domain or their translators have consented to online publication, as well as Shakespeare criticism, news archives (more than 3600) and popular essays. In 2011 the team launched the third project called Sovremenniki Shekspira - 'Shakespeare's Contemporaries' the aim of which is to bring together information on Elizabethan and Jacobean authors, as well as on theatre, court and university cultures at that time. ${ }^{17}$ The philosophy of the three interlinked websites combines the idea of an archive (of translations in particular) with that of a heterogeneous collection of Shakespeare-related materials (academic, artistic and popular), highlighting the Russian connections to the Shakespearean heritage. To serve the latter purpose, the site offer bibliographies of critical literature which elucidate e.g. Shakespeare's influence on Pushkin's poetry.

The two most recent and academically advanced Russian projects (Tools for Comparative Analysis of Russian Shakespeare Translations and Visualizing Shakespearean networks: Shakespearean references in the correspondence of Russian intellectuals) are currently being developed and they are not open for public browsing. The first project is a collaboration with the research team led by Tom Cheesman (Swansea University). ${ }^{18}$ The researchers first assemble excerpts from Russian translations of Othello, and then align them segment-by-segment with the original text. Further processing of data is expected to cast interesting light on the internal dynamics of the corpus of the play and its diachronic development. The addition of the Russian component is particularly valuable given the additional challenges stemming from Cyrillic script. The second project appears to be a colossal and long-term 
enterprise, and involves a visualization of letters and diary entries written by European scholars and men of letters in the 17-20th centuries which feature the mentions of Shakespeare or his works. Built on the Nodegoat platform developed by the Dutch startup LAB1100, the project will take an open and inclusive approach, including Russian authors from Pushkin to Dostoevsky, as well as Western scholars, actors, etc. The project will follow in the footsteps of the Critical Heritage series. Each digital entry will feature a Shakespeare-related excerpt, a link to the source, metadata and geotagging. Advanced visualization tools will allow display by date, territory, etc. Needless to say, should the project be completed, the resulting research tool shall inspire many hitherto impossible analyses of panEuropean literary influences and interdependencies.

The e-Repository of the Polish $19^{\text {th }}$ Century Shakespeare Translations: Resources, Strategies and Reception (Polski Szekspir - University of Warsaw) is a state-funded project aimed at establishing the repository of Polish translations of Shakespeare published in the nineteenth century, accompanied by essays on their translators, descriptions of translation strategies and notes on the literary and theatrical reception. ${ }^{19}$ The philosophy of the site aims at (1) completeness (the e-repository offers all of the complete nineteenth-century Polish translations of Shakespeare, making them available in PDF files as individual translations as well as translations with original paratexts), (2) academic research (all translations are interlinked with relevant critical resources and essays comprising the results of archival, analytical and comparative work), and (3) theoretical advancement (the site both offers and encourages theoretical reflection on the dynamics of retranslation processes and the impact of digital resources on the perception and stability of literary canons). The project involves three researchers at a time supported by the Digital Humanities Laboratory at the University of Warsaw.

The e-repository offers PDF files or TXT files based on OCR-versions, and (in a limited scope) text files with basic semantic structure. ${ }^{20}$ In the future, the e-repository should offer visualizations, indexes and other tools facilitating research. Additionally, the OCR texts (carefully checked with regard to their correctness) shall be compiled into packages for corpus analysis and made available on the e-repository website. The overall aim of the project is to scrutinise national translation resources, (re)assess the significance of both individual and collective translation endeavors, and open new vistas of research into the synchronic and diachronic dynamics of literary corpora. ${ }^{21}$

\section{(Dis)assembling the Black Boxes: Practicalities, Challenges, Afterthoughts}

The variety of the currently assembled national projects defies generalizations though it well exemplifies the conceptual options available to Shakespeare researchers willing to colonise digital spaces. The preliminary decision seems to pertain to the basic choice between a simple transposition of printed (or transcribed) texts into well-structured collections of digitalised files or an attempt at constructing flexible research environments composed of texts, (new) knowledge and advanced research tools. ${ }^{22}$ Thus the e-resources can be shaped into e-libraries, e-repositories, databases, machinereadable corpora or scholarly networks, all depending on the proportion of passive reproduction to active expansion of scholarly knowledge. Needless to say, the reliability of the e-resources stems always from the accuracy of those who construct them.

Some vital decisions pertain to the choice of software and file formats, both heavily depending on the availability of funding. On the one hand, free software often lacks necessary updates and in the long run may prove fatal for the project; on the other, the cost of commercial software frequently exceeds the budgetary constraints of research in humanities. Devoid of strong institutional support (such as Digital Humanities centres set up at universities), individual or isolated endeavours stand little chance of recognition, compatibility and sustainability in the rapidly evolving digital environment. ${ }^{23}$ As for the choice of file formats, one has to consider the often quite discordant interests of readers and digital scholars: while the former look for an easily downloadable and instantly usable text in a widely 
accepted format such as DOC or PDF (as in the case of Russkii Shekspir), the latter often need a platform-independent and metadata-rich format, ${ }^{24}$ since it greatly expands the tagging and searching opportunities, both within the text and across the structured metadata. Important decisions involve search options available for users since a good search functionality is one of the obvious advantages of electronic repositories or databases. In the projects considered in this paper, searches can generally be made to find words or phrases in the texts of the translations themselves, to find a given translation's electronic file (usually through a hyperlink to a PDF or HTML page), and to retrieve metadata and/or information on the translations.

Kapradi makes half of the digitised texts available in PDF in an online search tool that allows basic queries. In Shakespeare in Spain not all the PDFs are text-searchable, and some translations are split into individual PDFs for each act, which hinders searches for the whole play-text. Titles and translators have no search functionality: they can only be accessed via a web page listing the translations chronologically and grouped by translator. Both Russkii Shekspir and Polski Szekspir have full-text search across the HTML pages. The fact that the EMOTHE project is a full-text database will allow users to make searches of words, phrases, etc. in the whole corpus rather than in single texts.

Users can generally find a given translation file in the repository by means of search options that either use a free text search or select an item from a menu or list. Most projects offer searches by title, translator and year. The Polish project adds place and date of completion / publication. Kapradí even groups translators by generation, and distinguishes between date of composition and date of publication. In Russkii Shekspir translation files can also be accessed via a list of Shakespeare's works, generically arranged into histories, comedies, tragedies, tragicomedies, poems, and sonnets. In the online library of Shakespeare in Spain, titles, dates and translators can only be found by reading the web page listing the translations, which appear grouped by translator in a chronological order.

As far as metadata on the translations is concerned, Shakespeare on the Contemporary Italian Stage offers both a free text search and a guided search. The latter allows searches not only by the expected filters (play, year, venue, company, stage director, text type), but also through thematic search paths such as 'Adaptations and elaborations', 'From Shakespeare', 'The stage director and Shakespeare', 'Shakespeare by author' and others. These were chosen, on the basis of the actual problems encountered during the cataloguing process, rather than attempting to impose a pre-existing, fixed scheme on the raw data. The Polish repository allows users to search the collection by title (both English and Polish), translator, year, and place of completion / publication. Shakespeare in Spain has a database on translations up to 2005, containing basic information about title (in Spanish and in English), year, and translator, but entries are not hyperlinked to the corresponding texts in the online library. EMOTHE has not yet made available a search interface for the database of contextual information on each play.

The next step involves the prospects of integrating the repository with other national, European or global resources. These possibilities are based on two aspects: the prospective availability of TEIconformant XML files of the translations (only in EMOTHE and in Polski Szekspir), and the metadata included in the translation files. ${ }^{25}$

The major difficulties pertain usually to the availability and processing of the texts. Some obstacles appear fairly typical and stem from the usual miseries of archival research with missing resources, erroneous cataloguing or illegible handwriting. Additionally, the translations tend to be scattered over numerous locations, stored in uncatalogued private collections or institutional archives, or extant in multiple versions. A different set of problems arises with regard to contemporary rewritings which require permission from publishers and translators to be included in online collections. In some cases, the identification of the legal representative (or heir) turns out to be impossible. Such 'orphan texts' can be incorporated into the e-resources with relevant acknowledgement of copyright only. ${ }^{26}$ Sadly, commercial considerations are often responsible for the lack of the most recent translations in the online collections. And yet, given the specificity of modern book market, their absence from e- 
resources hardly boosts (or saves) sale figures, but it may impede new critical analyses which prompt further interest. Finally, the scholarly e-repositories face the ever intensifying curse of abundance due to the proliferation of online publications by amateur or dilatant translators seduced by the canonical status of Shakespeare. This combined with the ever tantalising status of adaptations, tradaptations and cultural hybrids, force scholars to devise qualifying criteria, based usually on quality assessment or temporal distance.

With all these challenges and limitations in mind, the e-repositories of Shakespeare translations appear to be an invaluable component of national literary and theatrical heritage. The translations bear witness to the dynamics and vitality of Shakespeare reception, but they also cast an important light on the evolution of target language(s), multiplying research opportunities for corpus linguistics or stylometry. As long as the methods of quantitative analysis suit best authorship studies, they inspire also some interesting questions as regards Shakespeare translations, providing that we find ways to process data in the multitude of target languages. ${ }^{27}$ If we do, the e-resources may help to isolate certain features which make the translations by a given translator linguistically distinct from those by other translators, as well as to identify time-bound or place-bound features of historically akin translations. Furthermore, it would be worthwhile to investigate the relation between linguistically distinct features of Shakespeare canon and those of translations. In other words, do translations reveal similar patterns as regards generic difference, chronological order, or collaboration practices? And last but not least, can quantitative methods isolate retranslations? Naturally, the answers to these questions are unlikely to shape future translation practices but they may enhance our assessments of translation value, discriminating originality from imitativeness, for instance.

\section{Glancing Towards the Future}

Beyond any doubt the construction and operation of the national e-resources of Shakespeare translations in the future shall hang on the fulfilment of the same conditions which apply to Digital Humanities at large. The teams of Shakespeare scholars will have to find IT solutions which match the academic needs of end-users and ensure their durability (i.e. updates, integration with new digital environments, and predictable cost). Another set of challenges will relate to accurate selection of relevant resources and development of efficient search and navigation tools, especially those bridging the gaps with adjacent disciplines such as corpus linguistics or stylometry. Ideally, the researchers will have tofind ways of interconnecting various national resources without relocating the files or converting them to other formats. This in turn could be greatly facilitated by setting up research groups willing to exchange experiences and work towards compatible solutions, at least with regard to resources originating in well-defined spatial or temporal limits. Needless to say, the European Shakespeare Research Association (ESRA) could be an ideal host to all such initiatives.

Above all, however, the e-repositories will call for the renewed understanding of the literary culture of past ages with obliterated divisions between the centre and the periphery, the major and the minor. The democratic access to the (near) totality of texts produced by a certain age does not warrant complete knowledge about that age but it does increase the reliability of findings. We cannot also forget about the cultural consequences of the (non)inclusion of many texts in the digitalised resources. The e-resources shall play a fundamental role in the construction of the images of past cultures, and may increase or petrify the distance between researchers and material sources. Thus in the long run the digital Shakespeare may become the only Shakespeare in translation we know, or produce. 


\section{Funding}

This article incorporates the research results of the state-funded projects The e-Repository of the Polish 19th Century Shakespeare Translations: Resources, Strategies and Reception 2016-2018 (NCN Opus 9, UMO-2015/17/B/HS2/01784), Teatro europeo de los siglos XVI y XVII: patrimonio y bases de datos (FFI2016-80314-P; Ministerio de Economía y Competitividad) and Entorno digital de investigación y traducción del primer teatro moderno inglés (GVAICO2016-094; Conselleria d'Educació i Cultura, Generalitat Valenciana).

\footnotetext{
${ }^{1}$ The idea of this article stems from the panel National Repositories of Shakespeare Translations: (Dis)assembling the Black Box held at the ESRA Conference in Gdańsk (2017). The panel (convened by Anna Cetera-Włodarczyk) brought together several national e-projects introduced by Pavel Drábek (Kapradi - The Electronic Library of Czech Translations of Early English Drama), Beatrice Montorfano (Shakespeare sulle scene italiane [Shakespeare on the Italian Stage]), Jesús Tronch (the online library of Spanish translations of the Shakespeare in Spain project; EMOTHE: Early Modern European Theatre and The HIERONIMO Project: Early Modern English Drama in Translation), Boris Gaydin, Vladimir Makarov, and Nikolay Zakharov (Russkii Shekspir, Mir Shekspira, and Sovremenniki Shekspira), and Anna Cetera-Włodarczyk (Polski Szekspir UW). While compiling the article we have consulted our French and German colleagues and there seems to be no analogous e-repositories other than those at the digital library Wikisource later mentioned. A beta version of the Hungarian Shakespeare Archive is available at https://msha.btk.ppke.hu. There have been no additional inquiries in other European countries. We are grateful to the Cahiers editors for pointing out the translations available at the website of the Ukrainian Shakespeare Centre http://shakespeare.zp.ua/texts.category.22/.

${ }^{2}$ Jerome McGann, A New Republic of Letters.Memory and Scholarship in the Age of Digital Reproduction (Cambridge MA, Harvard University Press, 2014), 5. For similar considerations see: Adriaan van der Weel, Changing Our Textual Minds:

Towards A Digital Order of Knowledge (Manchester and New York: Manchester University Press, 2011).

${ }^{3}$ Shakespeare in Europe, University of Basel, n.d. Available at https://shine.unibas.ch/ (accessed 30 May 2018)

${ }^{4}$ Kapradi is available at http://www.phil.muni.cz/kapradi/ (accessed 30 May 2018).

${ }^{5}$ Pavel Drábek, České pokusy o Shakespeara (Brno: Větrné mlýny, 2012). The book offers a critical history of Czech translations of Shakespeare with a theory of drama translation, a complete bibliography and a critical edition of some twenty rare or unknown early texts.

${ }^{6}$ Available at http://www.dislocazioni-transnazionali.it/ (accessed 30 May 2018).

${ }^{7}$ The project offers currently two segments (Shakespeare in print, Shakespeare re-written and Nineteenth Century Promptbooks of Shakespeare's 'Hamlet') both authored by Carla Dente and focused predominantly on some collaborative attempts at developing the hypertexts of English nineteenth-century Shakespeare promptbooks, and the third segment called Shakespeare sulle scene Italiane by Beatrice Montorfano, referred to in the main text.

${ }^{8}$ The main data source for this catalogue of Shakespeare productions in Italy is Patalogo, the annual review of the Italian stage which was published by Ubulibri from 1979 through to 2009. The issues considered for the project are those running from 1990 to 2009; additional material has also been gathered from other sources, though in a less systematic way.

${ }^{9}$ Available at https://www.um.es/shakespeare/traducciones/index.php (accessed 30 May 2018).

${ }^{10}$ The digital library is available at http://www.cervantesvirtual.com (accessed 30 May 2018)

${ }^{11}$ Available at http://emothe.uv.es/biblioteca/ (accessed 30 May 2018).

${ }_{12}^{12}$ P5: Guidelines for Electronic Text Encoding and Interchange. Available at http://www.tei-c.org/release/doc/tei-p5doc/en/html/index.html (accessed 30 May 2018).

${ }^{13}$ Available at http://artelope.uv.es/ (accessed 30 May 2018).

${ }^{14}$ Available at http://hieronimo.uv.es/en/home/ (accessed 30 May 2018).

${ }^{15}$ Available at http://www.rus-shake.ru/ (accessed 30 May 2018).

${ }^{16}$ Available at http://world-shake.ru/ (accessed 30 May 2018).

${ }^{17}$ Available at http://around-shake.ru/ (accessed 30 May 2018).

${ }^{18}$ The 'Version Variation Visualisation' project (www.delightedbeauty.org/vvvclosed) offers 'Translation Array Prototype 1' comprising thirty-seven digitised German versions (translations and adaptations from the years 1766-2010) of Act 1 scene 3 , which can be explored visually and algorithmically. See also Tom Cheesman, 'Reading Originals by the Light of Translations', Shakespeare Survey, 68 (2015), 87-98.

${ }^{19}$ The project is currently in the completion phase and shall be open to the public in March autumn of 2019. Meantime the team has obtained a new grant for the continuation of the project in the years 2018-2021. The second module of the erepository shall comprise the translations from the twentieth and twenty-first centuries.
} 


\footnotetext{
${ }^{20}$ One of the functionalities is the Comparative Engine which allows for simultaneous viewing of several translations. This is an external application, independent from the Omeka application working with the server that retrieves the translations through a special Application Programming Interface.

${ }^{21}$ Even though they are not repositories developed by an academic community and are vulnerable to criticism for unreliability, mention should be made of the "William Shakespeare" entries in the Wikisource libraries in different languages: the French, German, Czech and Russian pages offer most translations, accessible in transcriptions, OCR-scanned texts, and image facsimiles, either hosted by Wikisource or hyperlinked to other libraries (mainly national institutions, Project Gutenberg, and Google Books). For the French and German pages see https://fr.wikisource.org/wiki/Auteur:William_Shakespeare and https://de.wikisource.org/wiki/William_Shakespeare respectively (accessed 30 May 2018).

${ }^{22}$ For the discussion of the complexities of defining e-resources see Marlene Manoff, 'Theories of the Archive from Across the Disciplines', Portal: Libraries and the Academy, 4:1 (2004), 9-25.

${ }^{23}$ To illustrate the spectrum of opportunities, EMOTHE employs FileMakerServer for managing the database, FileMakerPro for accessing the database, Apple Server, and Oxygen for editing XML and transforming them into HTML and PHP - all highly reliable and expensive; and Polski Szekspir UW uses the free, open-source content management system Omeka, which works with LAMP servers (Linux, Apache, PHP, MySQL), thus putting trust in the sustained operation of the publisher, i.e. the American Centre for History and New Media. Similarly HIERONIMO employs free, open-source Wordpress for content management and MySQL for its databases, whereas Kapradi and Russkii Shekspir rely on a selfdesigned and self-supported software.

${ }^{24}$ With the use Extensible Markup Language defined by the guidelines of the Text Encoding Initiative (TEI-conformant $\mathrm{XML}$ ) as the best choice (as in EMOTHE and Polski Szekspir).

${ }^{25}$ In the case of the Polish project, the structure of the metadata is based on Dublin Core, although supplemented with categories to describe translations specifically, and can be accessed through the Open Archives Initiative Protocol for Metadata Harvesting (OAI-PMH), a generalised mechanism for repository interoperability, so that the structured metadata can be automatically imported and employed in similar projects as well as displayed in libraries and digital archives without having to duplicate the site where the file is stored

${ }^{26}$ The concept of 'orphan works' is defined by the European Directive 2012/28/EU. For the relevant regulations see:

http://ec.europa.eu/internal_market/copyright/orphan_works/index_en.htm (accessed 30 May 2018).

${ }^{27}$ For an overview of (new) research issues see: Hugh Craig, Brett Greatley-Hirsch, Style, Computers and Early Modern

Drama. Beyond Authorship (Cambridge: Cambridge University Press 2017).
} 